УДК 550.424.6:54.01(546.791+546.795):556:550.845

\title{
ФОРМЫ МИГРАЦИИ РАДИОНУКЛИДОВ (U и Тh) В ПРИРОДНЫХ ВОДАХ В РАЗЛИЧНЫХ ГЕОХИМИЧЕСКИХ УСЛОВИЯХ НА ОСНОВЕ РАСЧЕТНЫХ И ЭКСПЕРИМЕНТАЛЬНЫХ ДАННЫХ
}

\author{
Торопов Андрей Сергеевич1, \\ torop990@gmail.com
}

\section{Солдатова Евгения Александровна², sea@geokhi.ru}

\author{
Рихванов Леонид Петрович ${ }^{3}$ \\ 1 Московский государственный университет им. М.В. Ломоносова, \\ Россия, 119991, г. Москва, ул. Ленинские горы, 1. \\ 2 Институт геохимии и аналитической химии им. В.И. Вернадского Российской академии наук, \\ Россия, 119991, г. Москва, ул. Косыгина, 19. \\ 3 Национальный исследовательский Томский политехнический университет, \\ Россия, 634050, г. Томск, пр. Ленина, 30.
}

\begin{abstract}
Актуальность исследования обусловлена необходимостью учета разнообразия фоомм миграции природных радионуклидов при смене геохимических условий, а также при прогнозировании радиоэкологического статуса гидроэкосистем. На территории Семипалатинского испытательного полигона миграция естественных радионуклидов в водных системах слабо изучена, расчет форм миграции урана и тория при смене геохимических обстановок будет информативен для понимания миграции широкого спектра трансурановых радионуклидов.

Цель: определить формы миграции урана и тория в природных водах в зависимости от размеров частиц и с учетом широкого спектра компонентов, рассчитать формы их миграции в ручьях и озерах.

объекты: воды ручьев горного массива Дегелен, воды озер экспериментальных площадок Семипалатинского испытательного полигона, модельные гидрогеохимические системы.

Методы. Формы нахождения природных радионуклидов исследовали in situ методом каскадного фрракционирования природных вод. pH, Eh вод определяли методом потенциометрии, общую минерализацию - кондуктометрией. Определение основных ионов воды и отдельных элементов произведено методами титриметрии $\left(\mathrm{HCO}_{3}{ }^{-}, \mathrm{CO}_{3}{ }^{2-}, \mathrm{Cl}, \mathrm{Ca}^{2+}, \mathrm{Mg}^{2+}\right)$, оптико-эмиссионной спектрометрии ( $\mathrm{Na}, \mathrm{K}, \mathrm{Ca}, \mathrm{Mg}, \mathrm{Fe}$, Si), а также ионной хроматографрии (Cl, $\left.\mathrm{SO}_{4}{ }^{2-}\right)$. Содержание растворенных органических веществ определяли по перманганатной и бихроматной окисляемости, методом каталитического сжигания, а также по интенсивности UV сигнала. Содержание U и Th определяли методом масс-спектрометрии.

Результаты. Определены особенности переноса урана и тория в природных водах различных водных объектов Семипалатинского испытательного полигона, и обозначены определяющие их процессы. Установлено, что сульфат-ион в водах ручьев является индикатором интенсивности водообмена и скорости окисления сульфидных минералов, определяющих выход в раствор значительных концентраций урана. Уран связан с органическими и органоминеральными комплексами и подвержен трансформации форм нахождения в случае изменения геохимических условий среды. Для тория в большей степени, чем для урана, характерен коллоидный транспорт. Доминирующей миграционной формой этих элементов являются взвешенные компоненты природных вод. Отношение Th/U в растворенной форме достаточно стабильно по сравнению $с$ коллоидными и взвешенными фрормами. Для вод с разным гидродинамическим режимом прослеживается отличие в степени выраженности влияния терригенной составляющей.
\end{abstract}

\section{Ключевые слова:}

Уран, торий, коллоиды, моделирование, геохимические условия, миграция, уранилкарбонат кальция, радионуклиды, минералы.

\section{Введение}

Основным путем переноса различного рода загрязнителей на дальние расстояния, в том числе и радионуклидов, является водная среда. Особое внимание в этом вопросе уделяется трансурановым радионуклидам, имеющих самое длительное пребывание в биосфере с периодом полураспада миллионы и миллиарды лет.

Поведение радионуклидов в гидрогеохимических системах является актуальной научно-практической проблемой, наряду с интенсивностью и скоростью их миграции, а также влиянием радиоэлементов на здоровье человека [1]. В настоящее время выполнено существенное количество исследований по изучению поведения радионуклидов в экосистемах. На территории Средней Азии известны крупные месторождения урана, а также большие территории с повышенным содержанием естественных радионуклидов в почвах и горных породах, что может способствовать усиленной миграции природных радиоактивных элементов. При этом установлено, что главными параметрами, определяющими миграционный процесс, являются формы нахождения элементов и ландшафтногеохимические условия природной среды [2].

Экологическая опасность, создаваемая повышенной естественной радиоактивностью в пригодных для использования водных ресурсах [3], имеет место, например, при эксплуатации или рекультивации от- 
работанных или закрытых урановых рудников [4, 5], при разведке новых ресурсов подземных вод в Африке [6] и Ближнем Востоке [7], где соответствие питьевой воды гигиеническим нормативам по природным радиоактивным элементам довольно часто является проблемой. Поглощение урана из воды, почвы и воздуха живыми организмами в конечном итоге приводит к облучению человека. Добыча полезных ископаемых также может существенно усилить миграцию урана в результате изменения гидрологических и геохимических условий $[8,9]$.

Семипалатинский испытательный полигон (СИП) является одной из крупнейших мировых ядерных площадок, на которой в течение 40 лет в XX в. проводились испытания, изменившие облик данной территории и создавшие специфические условия миграции не только техногенных радионуклидов, но и многих других элементов, в значительной степени повлиявшие на перенос вещества. Ранее нами было показано, что техногенные радионуклиды $\left({ }^{239} \mathrm{Pu},{ }^{241} \mathrm{Am}\right.$ и др.) в поверхностных водах СИП содержатся в существенных количествах, и даже выше гигиенических нормативов, что может представлять опасность для человека и экосистем, перемещаясь за пределы площадок испытаний $[10,11]$. При этом миграция естественных радионуклидов в гидрогеохимических системах остается слабо изученной. Натурные исследования миграции и концентрирования тория и урана, а также расчет форм их миграции при смене геохимических обстановок также будут информативны для понимания условий миграции близких по свойствам других радионуклидов, в том числе и техногенных.

На территории СИП помимо техногенных факторов (ядерные испытания и эксперименты с радиоактивными веществами) имеется ряд природных факторов повышенной радиоактивности. Регион относится к ураноносной провинции, а некоторые локальные места (например, долина ручья Карабулак) являются урановыми аномалиями $[12,13]$. На фоне большого разнообразия гидрогеохимических обстановок (особенности рельефа, разгрузка подземных вод на поверхность, наличие горного массива, замкнутых водоемов различной глубины) поведение радионуклидов будет специфичным в каждом конкретном случае. На данной территории имеются природные воды самого различного состава - от пресных до соленых, богатые и бедные по растворенному органическому веществу, при этом концентрация урана и иногда тория выше фоновых значений.

Скорость переноса отдельных форм химических элементов может достигать значений, сопоставимых со скоростью движения природных вод [14]. Физикохимические механизмы переноса техногенных радионуклидов с водой недостаточно изучены. Это объясняется как методическими сложностями, так и объективной трудностью определения форм нахождения радионуклидов в водных системах из-за их низких и ультранизких количеств $[15,16]$.

На необходимость изучения форм нахождения радиоактивных элементов в системе растворколлоиды-взвешенное вещество указывают работы
[17, 18 и др.], ставшие уже классическими. В настоящее время происходит совершенствование аналитических методов, внедряются новые комбинированные инструменты для изучения фракционирования элементов, идентификации и определения геохимически и экологически значимых форм нахождения радионуклидов и ряда других значимых в экогеохимических исследованиях элементов в природных средах, что открывает совершенно новые возможности для улучшения прогностических моделей миграции вещества.

Обширный, но не исчерпывающий список методов изучения форм миграции урана, тория и других элементов в природных поверхностных водах приводится в обзоре S. Markich и P. Brown [19] и в [20]. Рaзличные варианты физического фракционирования химических элементов с выделением частиц по размеру получили наиболее широкое распространение по сравнению с выделением химических форм.

Среди них можно отметить работы по каскадному фракционированию (ультрафильтрации) с использованием набора мембран, включая ультрафильтрацию $[21,22]$, по проточному и тангенциальному фракционированию, позволяющие осуществлять мультидетекторное сопряжение либо использовать большой объем пробы [23-27 и др.].

Помимо этого, для выделения «размерных» форм миграции радиоактивных элементов использовались также диализ, гель-фильтрация и размероисключающая хроматография, капиллярный электрофорез [19], в том числе сопряженные с масс-спектрометрическим детектированием элементов в каждой выделяемой фракции $[19,28]$ для количественного определения уранильных комплексов с естественным растворенным органическим веществом (РОВ) в пресной поверхностной воде, а также для разделения $\mathrm{UO}_{2}{ }^{2+}$ и $\mathrm{U}^{4+}$.

Как правило, ни один метод не дает однозначной и исчерпывающей информации о формах миграции металла. Обычно выгодно комбинировать два и более метода или использовать схему выделения форм нахождения [19]. Различные варианты комбинации методов представлены в работах [27-32 и др.].

Единого мнения о том, является ли какая-либо конкретная методика выделения форм нахождения элементов в воде оптимальной, на сегодняшний день нет. Работоспособность той или иной схемы фракционирования форм миграции каждый раз нужно верифицировать. А набор наиболее подходящих инструментов (схем выделения конкретных форм нахождения, методик, создание гибридных методов и т. п.) будет зависеть от природы и характера образца, набора определяемых элементов. Важно, чтобы форма существования металла (радионуклида) не изменялась после отбора проб, хранения, предварительной обработки или самим аналитическим методом (например, при нарушении равновесных условий). Как показал наш опыт и подчеркивают многие исследователи [10, 15, 19-21], определение форм нахождения элементов было и остается нетривиальной задачей. В силу методических сложностей эксперимен- 
тальное выделение миграционных форм элементов выказывает высокие требования к профессионализму исполнителя и используемым аналитическим методам. Однако при отсутствии методологических ошибок даже сжатый набор методов может дать большое количество геохимической информации.

Химия и геохимия урана, как и многих других актинидов, осложнена способностью данного элемента к изменению степени окисления. В гидрогеохимических системах миграция урана контролируется $\mathrm{pH}$, окислительно-восстановительным потенциалом и рядом доступных комплексообразователей, таких как гуминовые вещества, карбонаты, фосфаты, сульфаты и т. д. [33].

Имеется и ряд неразрушающих методов, которые чаще всего могут дополнить общую картину понимания миграции радиоактивных элементов и ликвидировать «белые пятна» в вопросе форм нахождения и транспорта радионуклидов [34]. К таким методам относятся TRLFS и различные варианты спектроскопии рентгеновского поглощения (EXAFS, XANES) [35].

Большой вклад в понимание механизмов формирования различных форм миграции вносят и термодинамические методы расчета [36]. Чрезвычайное значение также имеет и достоверность термодинамических расчетов миграции радиоактивных элементов в условиях окружающей среды. Данные по константам равновесия урана достаточно обширны и детальны по сравнению с торием. Существует ряд термодинамических баз данных, например PRODATA (based on NEA-OECD TDB), Thermochimie, LLNL, Minteq, PSI/NAGRA и др., которые модифицируются или дополняются по мере необходимости, например, для уранилкарбонатов кальция и магния [37, 38]. Поскольку моделирование одного и того же состава воды с использованием различных баз данных может привести к весьма различным результатам [39], коррекция ионных сил растворов при моделировании и учет специфических комплексов являются критическими для расчетов [40].

Изучение миграции естественных радионуклидов урана и тория - с методологической точки зрения имеет ряд преимуществ благодаря их широкой распространенности в природных водах и возможности определения как радиометрически, так и массспектрометрически, что позволяет более четко выявлять специфику влияния геохимических условий на особенности миграции и других элементов, в том числе сложно определяемых техногенных радионуклидов.

\section{Объекты и методы исследования}

Территория Семипалатинского испытательного полигона находится в северо-восточной части Казахстана, в восточной части Казахского мелкосопочника, в условиях засушливого резкоконтинентального климата.

Пробы отбирались на основных испытательных площадках СИП (рис. 1):

«Опытное поле», где проводились наземные ядерные испытания в 1949-1961 гг. Водные объекты этой площадки - это воронки после наземных ядерных испытаний, заполненные водой и заросшие водной растительностью, чаще всего камышом. Для детального исследования взят один из таких водоемов - воронка В-1 (т. 1)

«Телькем» и «Балапан». Изучаемые водоемы представляют собой искусственные озера, образованные в результате экскавационных взрывов: Телькем-1 (т. 2) и Телькем-2 (т. 3); «Атомное» озеро (т. 4). Целью данных испытаний являлось создание искусственных водоемов в засушливом районе. «Атомное» озеро (другие названия озеро Чаган, Атомколь) сформировалось в результате заполнения водой воронки глубиной более 100 м и диаметром 400 м после взрыва в 1965 г. на месте слияния рек Шаган и Ащису (Ядерные испытания..., 1997; Semipalatinsk test..., 2017). Озера площадки «Телькем» образовались в 1968 г. в юго-восточной части СИП. Образованные воронки заполнились осадками и образовали одноименные озера «Телькем-1» с шириной 90 м и глубиной 15-20 м и «Телькем-2», вытянутое в форме овала озеро размерами $120 \times 60$ м и глубиной порядка $10-16$ м [41 и др.].

Площадка «Дегелен», на одноименном горном массиве, где сосредоточено самое большое количество водных объектов. Горный массив Дегелен находится в южной части СИП. В геологическом отношении преобладающая часть горного массива сложена гранитами, которые распространены на три четверти территории. В горном массиве Дегелен выделяют трещинные воды палеозойских пород, поровые воды аллювиально-пролювиальных отложений, куда относят и подрусловые воды. Юго-восточное направление подземных вод является основным и совпадает с направлением долины ручья Узынбулак. Трещинные воды образуют единый водоносный горизонт.

Исследованы самые крупные ручьи Узынбулак (т. 5) на месте выхода ручья за пределы площадки «Дегелен» и Карабулак с его притоками (т. 6-11). Общее количество проб, обсуждаемых в работе, составило 11.

В местах расположения испытательных площадок СИП проходят разломы глубокого залегания, которые определяют неоднородную фильтрационную способность пород. К основным разломам относят: КалбаЧингизский разлом на испытательной площадке «Опытное поле», Найманжальский разлом площадки «Телькем», и Чинрауский разлом площадки «Балапан». Зоны влияния тектонических разломов характеризуются более высокими показателями трещиноватости и наличием зон дробления. Это является неблагоприятным фактором для транспорта загрязненных радионуклидами вод в подземные воды территорий, где не имеется следов загрязнения.

Отбор проб природных вод проводился в соответствии с ГОСТ 17.1.5.05-85. Объем проб воды составлял 10-12 л. Пробу отбирали в чистые полиэтиленовые емкости, избегая попадания посторонних примесей. На месте отбора проводили фракционирование воды по размеру с фильтрованием через мембраны 450 нм и 10 кДа (соответствует размеру 3 нм). Таким образом, выделяли взвешенные формы (разница между нефильтрованной пробой и после фильтра 450 нм), коллоидные формы (разница между пробами, отфильтрованными через мембраны 450 нм и 10 кДа) и растворенные формы (<10 кДа). 


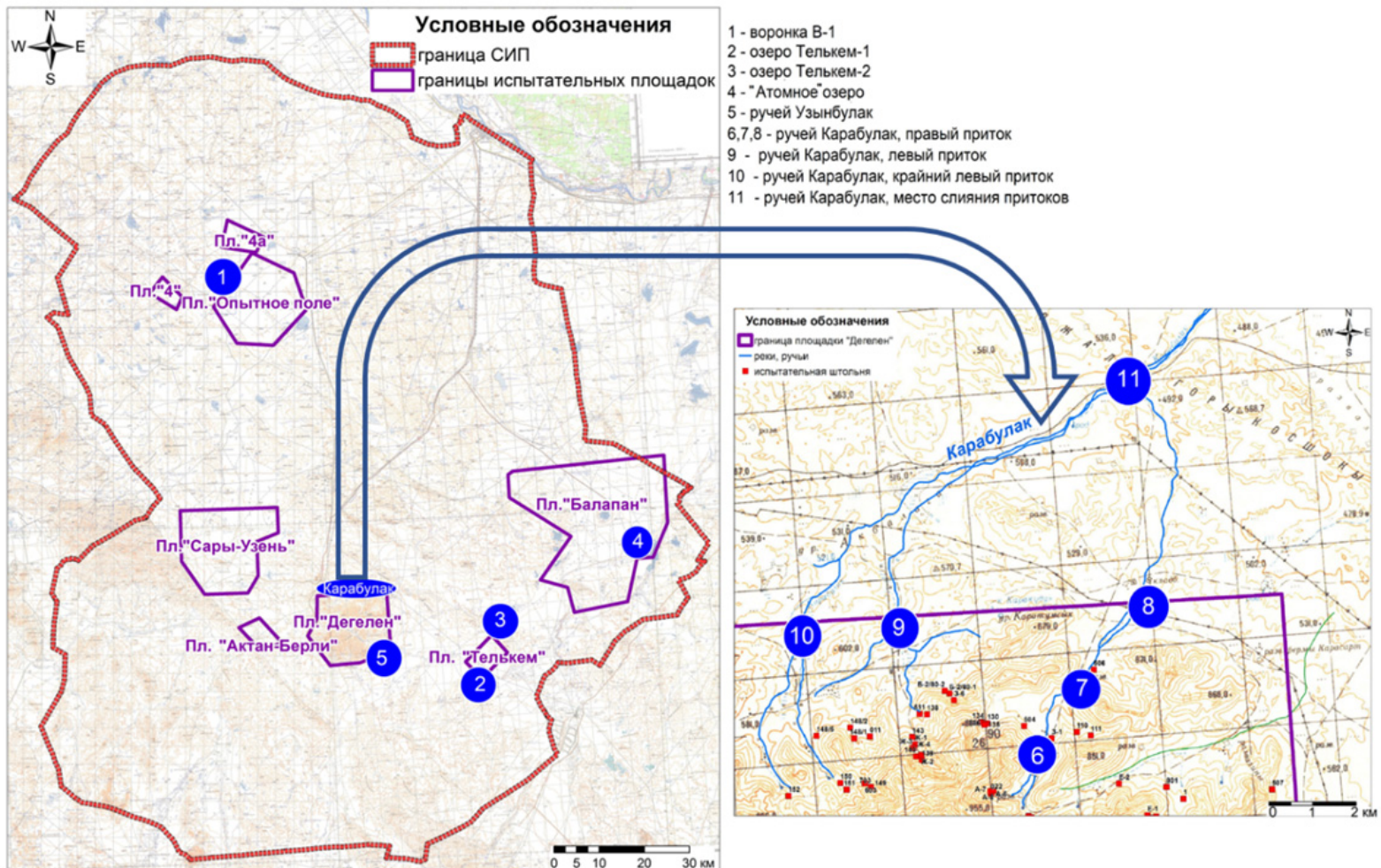

Pис. 1. Схема опробования водных объектов

Fig. 1. Scheme of water bodies sampling

Определение общей минерализации и рН и Еһ воды выполняли с помощью анализатора жидкости лабораторного серии Анион 4100. Еh воды измерялся с хлорсеребряным электродом сравнения с последующим пересчетом на стандартный водородный электрод (SHE) при температуре $25{ }^{\circ} \mathrm{C}$. Содержание основных ионов воды определяли методами титрования $\left(\mathrm{HCO}_{3}^{-}, \mathrm{CO}_{3}{ }^{-}\right)$, $\mathrm{Cl}^{-}, \mathrm{Ca}^{2+}, \mathrm{Mg}^{2+}$, фотометрии $\left(\mathrm{SO}_{4}^{2-}\right)$, оптикоэмиссионной спектрометрии на приборах іCAP 6300 Duo и Optima8300DV (Na, K, Ca, Mg), а также ионной хроматографии на приборе Dionex-2000 $\left(\mathrm{Cl}^{-}, \mathrm{SO}_{4}{ }^{2-}\right)$. Общий органический углерод оценивался по перманганатной и бихроматной окисляемости (титрование и фотометрия соответственно). Для части образцов использовался метод каталитического сжигания на прибope Vario TOC cube, а также качественный метод интенсивность UV сигнала (UV Schimadzu 1800) в диапазоне от 225 до 280 нм. Содержание U и Th определяли методом масс-спектрометрии с индуктивно связанной плазмой (MC-ИСП) на приборах Elan-9000, Agilent 7600, Thermo Element XR в соответствии со стандартом ИСО 17294-2-2006.

Моделирование миграционных форм урана и тория проводилось с помощью программного комплекca Visual Minteq 3.1. Использовалась встроенная база данных констант равновесия. Расчет проводился при температуре $25^{\circ} \mathrm{C}$, давлении 1 атм и равновесном с атмосферой парциальным давлении углекислого газа. Модель была ограничена следующими компонентами: $\mathrm{pH}$, $\mathrm{Eh}$, общая щелочность $\left(\left(\mathrm{CO}_{3}{ }^{2-}+\mathrm{HCO}_{3}^{-}\right), \mathrm{Cl}^{-}, \mathrm{SO}_{4}^{2-}\right.$, $\mathrm{Ca}^{2+} \mathrm{Mg}^{2+}, \mathrm{Na}^{+}, \mathrm{K}^{+} \mathrm{Si}\left(\mathrm{H}_{4} \mathrm{SiO}_{4}\right), \mathrm{Fe}^{3+}, \mathrm{UO}_{2}{ }^{2+}, \mathrm{Th}^{4+}$, pacтворенный органический углерод $\left(\mathrm{C}_{\text {орг }}\right)$. Расчет органических форм миграции элементов проводили с по- мощью модели NICA-Donnan с раздельным введением концентраций гуминовых (ГК) и фульвокислот (ФК). Отношение активного (способного к биотрансформации) $\mathrm{C}_{\text {орг }}$ к органическому углероду принимали как 1,65 , долю ФК учитывали исходя из соотношения ГК/ФК. Ионная сила раствора и баланс анионов и катионов рассчитывались автоматически. Коррекция активности ионов проводилась по уравнению Дэвиса $\mathrm{c}$ b-параметром равным 0,3 .

\section{Результаты и их обсуждение}

Изученные водные объекты СИП представляют собой водоемы и ручьи, которые существенно различаются по условиям миграции радионуклидов.

По химическому составу и преобладающим ионам воды горного массива Дегелен относятся к пресным водам сульфатного, кальциевого и гидрокарбонатносульфатного кальциевого состава. По данным [42-44] химический состав вод стабильный и не зависит от сезона. Перемещаясь по системам трещин и полостям штолен, воды пополняют бассейн подземных вод либо выходят на дневную поверхность в районе порталов штолен.

Изученные воды существенно различались по химическому составу, хотя и прослеживались схожие условия их формирования. Изучаемая территория характеризуется широким набором условий формирования поверхностных вод и достаточно пестрой геохимической обстановкой. На формирование химического состава природных вод СИП оказывают влияние механизмы испарительного концентрирования и континентального засоления, выщелачивания водовмещающих пород в условиях повышенной трещи- 
новатости и образования большого количества зон дробления в результате деформации горного массива Дегелен вследствие ядерных испытаний.

Как уже было сказано ранее, водоисточники представлены техногенными озерами и воронками, а также ручьями и реками.

Таблица 1. Химический состав природных вод Семипалатинского испьтательного полигона среднее содержание (минимум-максимум)

Table 1. Chemical composition of natural waters of Semipalatinsk Test Site (STS), mean (minimummaximum)

\begin{tabular}{|c|c|c|}
\hline $\begin{array}{l}\text { Показатель, ед. изм. } \\
\text { Parameter, units }\end{array}$ & $\begin{array}{c}\text { Ручьи/Riverstreams } \\
(\mathrm{n}=7)\end{array}$ & $\begin{array}{c}\text { Oзepa/Lakes } \\
(\mathrm{n}=4)\end{array}$ \\
\hline $\mathrm{pH}$ & $7,44(7,14-7,91)$ & $7,92(7,20-8,36)$ \\
\hline $\mathrm{Eh}_{\mathrm{SHE}}, \mathrm{mB} / \mathrm{mV}$ & $249(208-260)$ & $186(152-207)$ \\
\hline $\begin{array}{l}\mathrm{C}_{\text {орг }}, \mathrm{Mг} / \mathrm{л} / \text { Dissolved } \\
\text { organic carbon, mg/1* }\end{array}$ & $12,8(9,6-16)$ & $14(5-35)$ \\
\hline $\begin{array}{l}\Phi \mathrm{\Phi} / \Gamma \mathrm{\Gamma} / \mathrm{FA} / \mathrm{HA} \\
\text { (humic acid/fulvic acid) }\end{array}$ & 9,5 & 7 \\
\hline $\begin{array}{l}\text { Минерализация, мг/л } \\
\text { TDS, mg/l }\end{array}$ & $472(235-2310)$ & $10950(1960-20520)$ \\
\hline $\mathrm{HCO}_{3}^{-}, \mathrm{Mг} / \mathrm{\Omega} / \mathrm{mg} / \mathrm{l}$ & $171(67-490)$ & $332,5(180-530)$ \\
\hline $\mathrm{SO}_{4}^{2-}, \mathrm{M \Gamma} / \mathrm{I} / \mathrm{mg} / \mathrm{l}$ & $221(79-1100)$ & $3345(600-7580)$ \\
\hline $\mathrm{Cl}^{-}, \mathrm{M \Gamma} / \mathrm{л} / \mathrm{mg} / 1$ & $15(5,5-210)$ & $3705(420-5950)$ \\
\hline $\mathrm{Ca}^{2+}, \mathrm{M \Gamma} / \mathrm{\pi} / \mathrm{mg} / \mathrm{l}$ & $93(54-120)$ & $380(120-540)$ \\
\hline $\mathrm{Mg}^{2+}, \mathrm{M \Gamma} / \mathrm{\pi} / \mathrm{mg} / \mathrm{l}$ & $18,5(8-76)$ & $512(80-910)$ \\
\hline $\mathrm{Na}^{+}+\mathrm{K}^{+}, \mathrm{Mr} / \mathrm{I} / \mathrm{mg} / \mathrm{l}$ & $39,5(17-560)$ & $2845(480-5450)$ \\
\hline $\mathrm{Si}, \mathrm{M \Gamma} / \mathrm{J} / \mathrm{mg} / \mathrm{l}$ & $6(4,5-10)$ & $3(2,2-3,8)$ \\
\hline 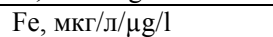 & $210(180-240)$ & $330(90-600)$ \\
\hline $\mathrm{Ca}^{2+} / \mathrm{Mg}^{2+}$ & $5,0(1,6-8,4)$ & $0,92(0,59-1,50)$ \\
\hline $\mathrm{SO}_{4}{ }^{2-} / \mathrm{Cl}^{-}$ & $16,4(5,2-53,3)$ & $0,97(0,47-1,43)$ \\
\hline
\end{tabular}

$n$ - количество проб/n - number of samples; *Для водоемов Телькем-1 и Телькем-2 при расчете среднего содержания $C_{\text {орг }}$ использовалось значение половины предела обнаружения/*For Telkem-1 and Telkem-2 lakes the half of the detection limit was used for mean value of DOC.

По значениям $\mathrm{pH}$ (табл. 1) воды большинства опробованных ручьев и воронки В-1 были нейтральными, воды объектов Телькем-1, Телькем-2 и «Атомного» озера - слабощелочными. Значения Eh (приведенный к стандартному потенциалу и $25^{\circ} \mathrm{C}$ ) природных вод СИП укладываются в диапазон $+150 \ldots+260$ мВ, выстраиваясь в ряд в зависимости от $\mathrm{pH}$ на 600 700 мВ выше нижней границы предела устойчивости воды и на 200-300 мВ ниже равновесия взаимодействия воды с атмосферой [45]. Для всех водных объектов характерна переменная окислительновосстановительная обстановка.

Вода водоемов В-1 и Телькем 2 относится к солоноватым водам (1960 и 8950 мг/л соответственно) Воды озера Телькем-1 (20520 мг/л), «Атомного» озеpa (12380 мг/л) - к соленым водам. Воды ручьев были пресными, за исключением места слияния притоков ручья Карабулак, где вода была солоноватой.

По ионному составу поверхностные воды СИП достаточно разнообразны. Основные геохимические фации были выделены по преобладающим анионам и катионам с помощью диаграммы Пайпера (рис. 2) При этом четкая дифференциация наблюдается между водоемами и ручьями. Рост минерализации штольневых вод обеспечивается увеличением содержания в них гидрокарбонат-иона, кальция, магния, а также сульфат-ионов.

Воды ручьев имеют близкий состав со штольневыми водотоками, поскольку последние подпитывают их [10]. Воды ручьев Узынбулак и Карабулак по составу сульфатные кальциевые. Отношение $\mathrm{SO}_{4}{ }^{2-} / \mathrm{Cl}^{-}$в ручьях изменяется в пределах от 5,2 до 53. Это позволяет предположить, что состав вод ручьев формируется под влиянием процессов выщелачивания минералов водовмещающих пород и окисления сульфидных минералов. На диаграмме Пайпера (рис. 2) во всех плоскостях точки ручьев лежат очень близко друг к другу и при этом занимают промежуточное положение по отношению к составу штольневых вод. Таким образом, при смешивании вод мелких ручьев и родников, подпитывающих ручьи массива Дегелен, происходит «выравнивание» их химического состава. Это можно принимать во внимание при оценке миграции радиоактивных элементов вниз по течению ручьев.

Поверхностные водоемы находятся в зоне влияния континентального засоления с изменением отношения $\mathrm{SO}_{4}{ }^{2-} / \mathrm{Cl}^{-}=1,4$ в водах водоема В-1, озера Телькем$1-1,2$, «Атомного» озера - 0,7, озера Телькем-2 - 0,5. Воды водоемов по составу являются хлоридными и хлоридно-сульфатными. Преобладающие анионы, а также натрий пропорционально увеличиваются с ростом минерализации в водоемах, отношение $\mathrm{Ca}^{2+} / \mathrm{Mg}^{2+}$ также снижается.

Содержание органического углерода в ручьях варьировало от 10 до 16 мг/л, в водоемах достигало 35 мг/л (Воронка В-1). Для части проб не было получено количественных значений из-за низкой чувствительности методов определения органического вещества в пробах со сложной матрицей и высокой минерализацией. Однако в водах, где содержание растворенного органического углерода было ниже предела обнаружения, в частности для озера Телькем-2, гуминовые и фульвокислоты фиксировались качественно по поглощению УФ-спектра.

Обращаясь к ранее проведенным исследованиям, необходимо отметить, что водный режим и характер питания также могут оказать влияние на миграцию радиоактивных элементов и распределение форм их нахождения. Отношение стабильных изотопов ${ }^{2} \mathrm{H} /{ }^{18} \mathrm{O}$ свидетельствует о питании водоема за счет атмосферных осадков $[10,11]$, поскольку воды озера Телькем-2 и водоема В-1 лежат очень близко к локальной линии метеорных вод. Небольшие сдвиги изотопного состава в местах отбора проб могут объясняться конденсированием испарённой влаги с водного зеркала озера в поверхностном слое [46]. Такие данные не противоречат выводам авторов, исследовавших «Атомное» озеро [47 и др.], о том, что основной источник поступления радионуклидов в водоем выщелачивание из загрязненного грунта. Это позволяет распространить такое суждение и на другие водоемы Семипалатинского полигона.

Также ранее установлено [11], что штольневые воды, подпитывающие ручьи горного массива Дегелен, по отношению ${ }^{2} \mathrm{H} /{ }^{18} \mathrm{O}$ утяжелены по дейтерию в сравнении с локальной линии метеорных вод. Такое рас- 
пределение можно объяснить испарительным концентрированием инфильтрационных вод метеогенного формирования. Также возможно существование дополнительного источника питания вод в условиях относительной литологической и гидрогеологической закрытости, с отличным от линии метеорных вод от- ношением ${ }^{2} \mathrm{H} /{ }^{18} \mathrm{O}$. Левосторонний сдвиг $\Delta^{2} \mathrm{H}$ относительно линии метеорных вод можно также объяснить и активным истощением ${ }^{18} \mathrm{O}$ вследствие его перехода в карбонатные отложения и углекислоту, а также отставанием вовлечения дейтерия во вторичные минералы в процессе взаимодействия вода-порода [48].
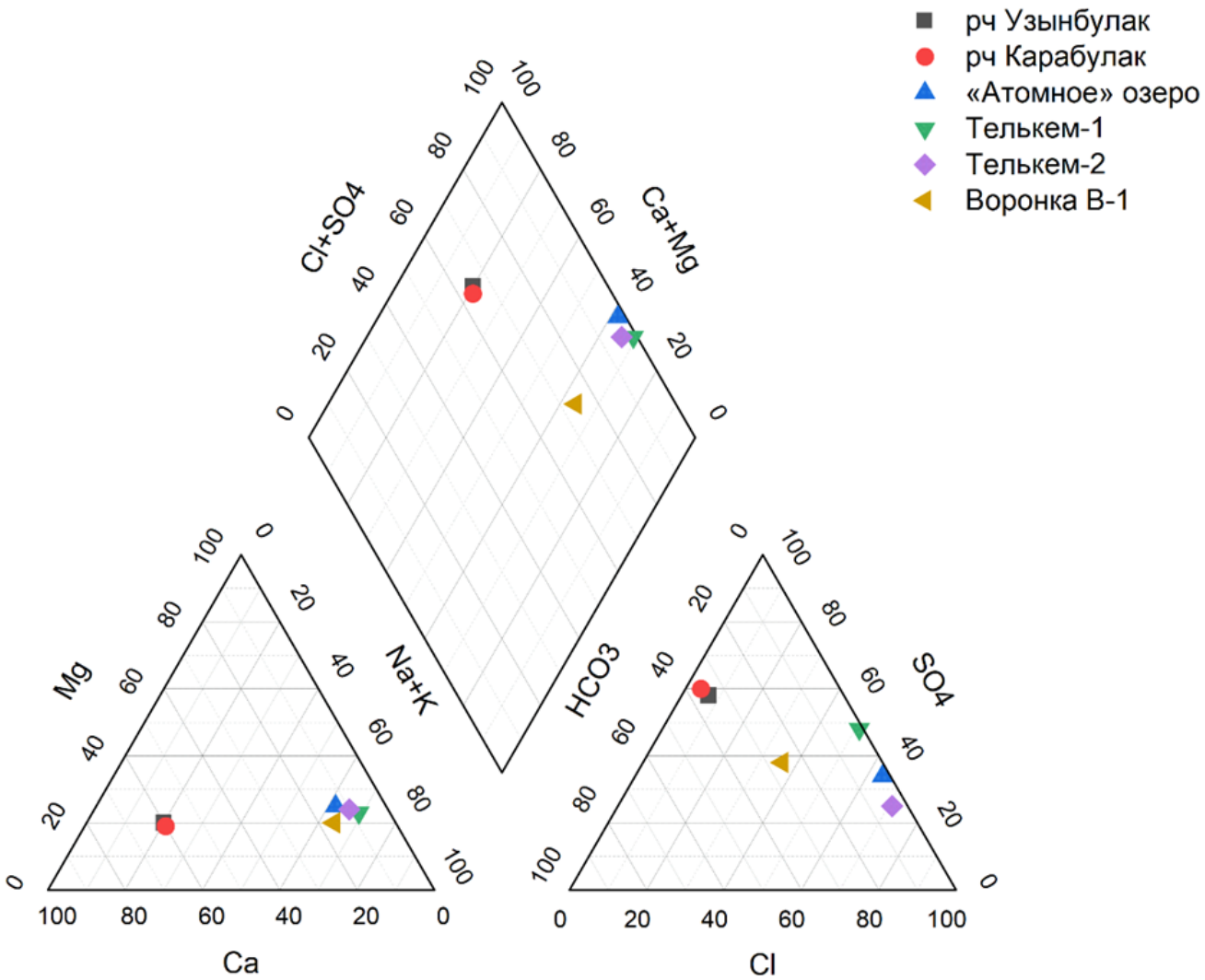

Pис. 2. Пайпер-диаграмма химического состава озер и ручьев СИП

Fig. 2. Piper diagram of chemical composition of lakes and waterstreams of STS

Таблица 2. Распределение радионуклидов в водных объектах СИП и формы их нахождения, среднее значение (минимум-максимум)

Table 2. Distribution of radionuclides and their speciation in water bodies of STS, mean (minimum-maximum)

\begin{tabular}{|c|c|c|}
\hline $\begin{array}{l}\text { Показатель, ед.изм. } \\
\text { Parameter, units }\end{array}$ & $\begin{array}{c}\text { Ручьи/Riverstreams } \\
(\mathrm{n}=7)\end{array}$ & $\begin{array}{c}\text { Oзерa/Lakes } \\
(\mathrm{n}=4)\end{array}$ \\
\hline $\mathrm{Th}_{\text {вал}} / \mathrm{Th}_{\text {total }}$, мкг $/ \mathrm{л} / \mu \mathrm{g} / 1$ & $0,43(0,11-0,59)$ & $19,1(4,5-46)$ \\
\hline $\mathrm{Th}_{\text {взвеш }} / \mathrm{Th}_{\text {susp }}, \%$ & $89(84-92)$ & $88,4(75,4-94,4)$ \\
\hline $\mathrm{Th}_{\text {колл }} / \mathrm{Th}_{\text {соll, }}, \%$ & $9,2(7,6-11,4)$ & $11,1(5,3-24,4)$ \\
\hline $\mathrm{Th}_{\text {раств}} / \mathrm{Th}_{\text {diss }}, \%$ & $1,5(0,8-2,4)$ & $0,42(0,1-0,9)$ \\
\hline 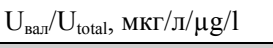 & $110(32-810)$ & $202(10,6-2567)$ \\
\hline $\mathrm{U}_{\text {взвеш }} / \mathrm{U}_{\text {susp }}, \%$ & $55(47-82)$ & 84,5 (49-98) \\
\hline $\mathrm{U}_{\text {колл }} / \mathrm{U}_{\text {coll }}, \%$ & $13(5-15)$ & $3,6(0,5-12)$ \\
\hline $\mathrm{U}_{\text {раств }} / \mathrm{U}_{\text {diss }}, \%$ & $32(10-42)$ & $12(2-39)$ \\
\hline
\end{tabular}

Примечание: серым иветом выделены строки с формами нахождения радионуклидов.

Note: speciation of radionuclides is highlighted gray.

Валовое содержание тория (табл. 2) в природных водах СИП изменяется в широких пределах, более двух порядков - от 0,11 до 46 мкг/л. При этом, если отсечь взвешенную фракцию (крупнее 450 нм), сумма оставшихся фракций, которая наиболее часто рассматривается в исследованиях по гидрогеохимии радиоактивных элементов как растворенная форма, составит от 0,014 до 3,7 мкг/л соответственно. Видно, что доминирует взвешенная форма в переносе тория и урана. При этом доля переносимого со взвесями тория примерно одинаковая как для ручьев, так и для озер. В то время как для урана отмечена существенная разница. В ручьях гораздо большая доля урана мигрирует в форме растворенных частиц, проходящих через мембрану 10 кДа. Доля урана, мигрирующего в водах ручьев с частицами коллоидной размерности, примерно в три раза выше, чем в водоемах.

Содержание урана в изучаемых природных водах аналогично изменяется в диапазоне двух порядков. При этом концентрация данного радиоактивного элемента (<450 нм) в водоемах меньше: от 5,5 мкг/л (B-1) до 66 мкг/л (Телькем-2). В ручьях горного массива Дегелен общее содержание урана составляет 60 и 81 мкг/л для ручьев Карабулак и Узынбулак соответственно.

Доля мигрирующего в коллоидной форме урана в водотоках массива Дегелен невысока, от 5 до $15 \%$. Однако, учитывая высокие концентрации этого ра- 
диоактивного элемента и особенности миграции элементов в коллоидных формах, это может свидетельствовать о значимом выносе урана с коллоидами. В водоеме В-1 и ручье Карабулак доля урана, который мигрирует в коллоидной форме, выше, что может объясняться более высоким содержанием органического вещества, замедленным водообменом и высокой концентрацией коллоидов.

Для тория также было установлено преобладание взвешенной формы (от 75 до $91 \%$ от суммы всех форм нахождения). В среднем порядка $12 \%$ тория переносится в изученных водоисточниках с коллоидами, с максимумом для водоема В-1 (24 \%).
Для ручья Карабулак преобладает взвешенная форма урана и тория. Было подробно изучено изменение форм нахождения в пространстве (рис. 3). Ближе к истокам ручьев горного массива происходит разгрузка подземных вод, обогащенных радионуклидами. Несомненно, в этих водотоках присутствуют и техногенные радионуклиды, что было показано нами в более ранних работах. Однако в связи со значительной деформацией массива и увеличением проницаемости пород скорость выщелачивания природных радионуклидов могла существенно увеличиться, а миграция - ускориться.
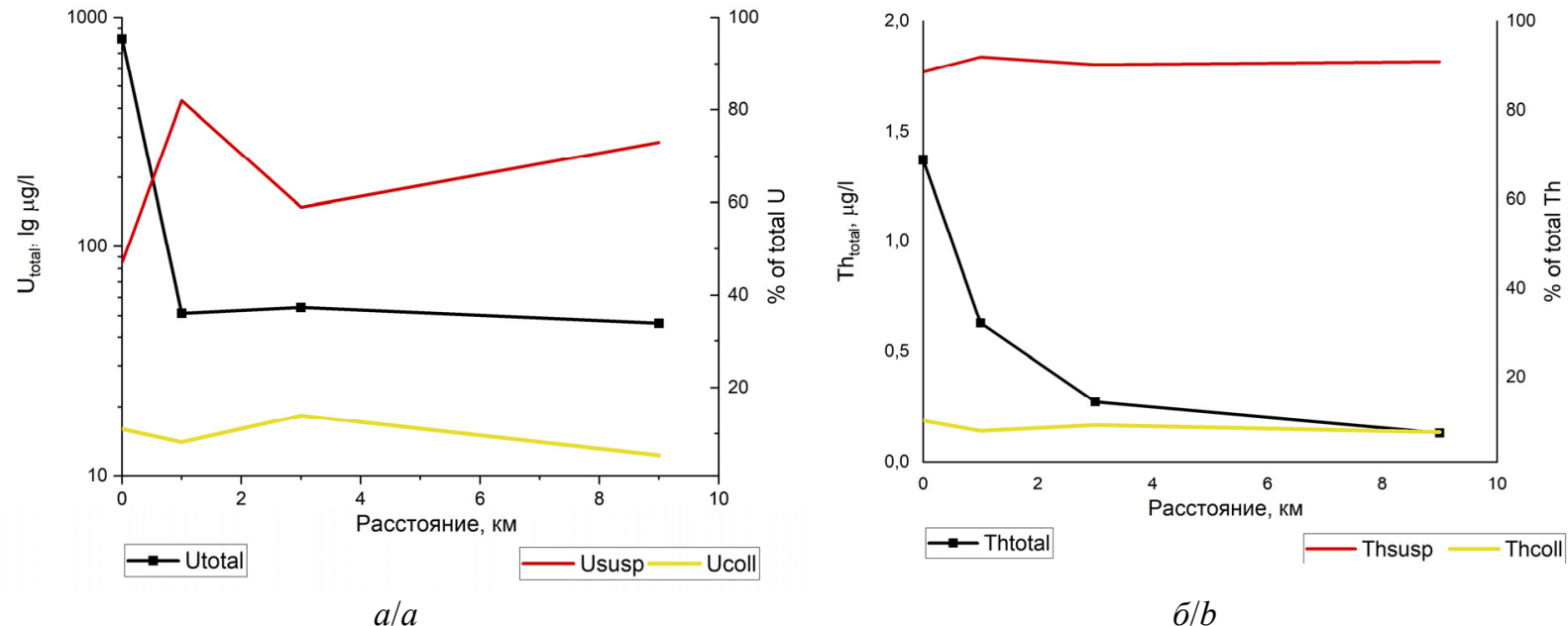

Pис. 3. Распределение тория, урана и долей коллоидной и взвешенной фракиий в правом притоке ручья Карабулак от истока до места слияния притоков: а) распределение валового содержания и доли форм нахождения $U$; б) распределение валового содержания и долей форм нахождения Тh. Красной и желтой линией выделены доли форм нахождения урана и тория в виде взвесей и коллоидов соответственно, черной линией-общее содержание элементов

Fig. 3. Distribution of thorium, uranium and the proportions of colloidal and suspended fractions in the right tributary of the Karabulak riverstream from the headspring to the confluence of the tributaries: a) distribution of the total content and the proportion of U species; b) distribution of the total content and the proportion of Th species. The red and yellow lines show the proportions of the uranium and thorium in suspended and colloidal fractions respectively, the black line is the total content of elements

Одной из задач исследования стояло изучение трансформации миграционных форм радионуклидов вниз по течению от источников их поступления. Наиболее показательным для таких наблюдений был участок правого притока ручья Карабулак, где существует подток вод с повышенным содержанием урана (более 800 мкг/л урана и 3 мкг/л тория, по собственным исследованиям). Протяженность участка составила порядка 9 км. Расстояние между первыми тремя точками - 1,5 км, крайняя точка находится в 9 км от первой. В целом соотношение форм нахождения кардинально не меняется от точки к точке отбора, но уменьшается общее содержание радиоактивных элементов. Максимальное содержание урана и тория приурочено к истоку ручья (точка 6, рис. 1), где имеются источники поступления этих радионуклидов со штольневыми водами. Ниже по течению ручья, при достижении точки 11 (место слияния притоков), содержание урана падает примерно на порядок, а содержание тория - в 3-6 раз. Таким образом, Th/U от- ношение по сумме форм нахождения повышается к месту слияния притоков ручья Карабулак. Возрастает роль коллоидов в переносе радиоактивных элементов на фоне снижения общего их содержания.

Наблюдая за распределением форм нахождения этих двух элементов, отмечено, что формы урана более чувствительны к изменению ландшафтногеохимических условий среды, чем тория. Так, в пределах 3 км доля коллоидной формы урана изменялась почти в два раза - от 8,2 до 14 \%, в то время как ионный состав и минерализация вод ручья были примерно одинаковые. Вероятно, на данном участке происходит перераспределение форм нахождения, обратимая сорбция взвесями ручья и захват урана коллоидными частицами. Далее на фоне повышения солесодержания (от 450 до 2300 мг/л) в месте слияния притоков ручья Карабулак из-за механизма испарительного концентрирования и снижения интенсивности водообмена доля коллоидного урана сокращается в 3 раза. В то же время доля коллоидной и взвешенной фракций тория 
(рис. 3, б) остается на одном уровне несмотря на то, что его концентрация снижается на порядок.

Соотношение отдельных элементов - часто применяемый параметр, который может быть четким индикатором геохимических процессов и интенсивности миграции элементов. Иногда такие параметры более информативны, чем валовое содержание элементов в отдельности. Так, известный в геохимии радиоактивных элементов параметр, отношение Th к U [49], преимущественно используется в геохимии минералов и горных пород, а также их датировке. И теоретическое рассчитанное, и экспериментально установленное отношение $\mathrm{Th} / \mathrm{U}$ в земной коре на сегодняшний день укладывается в диапазон 3-4 [50], с весьма широким диапазоном в горных породах разного состава. Однако в водах гидросферы в подавляющем большинстве экспериментальных исследований [50, 51] значение много меньше единицы $\left(\mathrm{Th} / \mathrm{U}=10^{-3}-10^{-5}\right)$, однако встречаются в исключительных случаях воды c Th/U выше единицы и более. Величина этого показателя для океанических вод, доля которых составляет $98 \%$ вод гидросферы, в среднем равна 0,0036 [4951]. Для крупнейшего по запасам пресной воды озера Байкал данная величина в среднем составляет 0,007 [49].

В исследованных водных объектах $\mathrm{Th} / \mathrm{U}$ составило: для ручьев 0,0011 , для водоемов почти в три раза выше - 0,0028. Это можно объяснить замедленным водообменом в водоемах, где создаются благоприятные условия для перехода тория в коллоидное состояние, либо, напротив, более активное осаждение урана со вторичными минералами, достигнувшими насыщения в солоноватой воде озер и выпадающими в осадок. В воде водоемов $\mathrm{Th} / \mathrm{U}$ выше почти на порядок, вероятно, за счет более медленного водообмена и обогащения воды торием в процессе выщелачивания из горных пород.

Другой задачей работы был расчет доминирующих форм миграции природных радионуклидов в растворенной форме. Поскольку применение экспериментальных методов выделения форм миграции на сегодняшний день затруднительно для тех количеств радионуклидов, которые присутствуют в природных водах, успешно применяются расчетные методы на основе известных термодинамических констант, произведений растворимости отдельных компонентов и наличия комплексообразующих веществ. По термодинамическим расчетам, преобладающей формой миграции урана в водах данного состава, в диапазоне экспериментальных значений $\mathrm{pH}$ и Eh, будут уранилкарбонатные комплексы (LNLL, OECD-NEA). Для тория расчеты показывают наиболее вероятную форму его нахождения при построении $\mathrm{pH}-\mathrm{Eh}$ диаграмм $\mathrm{ThO}_{2} \mathrm{cr}$, торианит (LNLL, JNC-TDB). Однако это утверждение будет справедливо для растворенных форм нахождения при отсутствии комплексообразователей. Наличие в воде комплексообразователей, растворенных органических веществ и коллоидов различной размерности искажает идеальную картину, получаемую при применении таких расчетов и моделирования по существующим константам равновесия. Даже более детальный расчет с учетом содержания основных ионов воды и органических веществ, приведенный на рис. 4, 5, который демонстрирует возможность миграции урана в виде уранилкарбоната кальция, а также обоих элементов в виде фульво- и гуматных комплексов, не учитывает в полной мере геохимического облика всех водных систем.
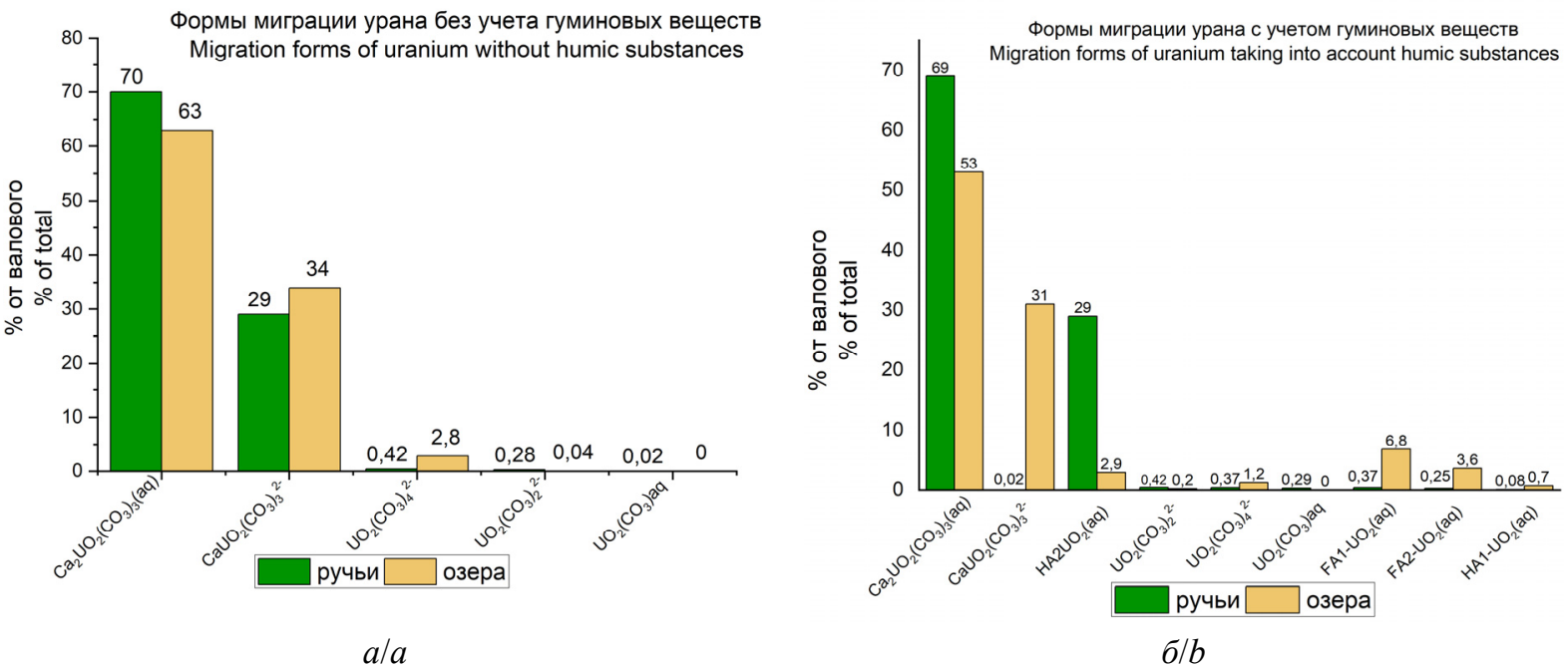

Рис. 4. Формы миграчии урана в ручьях и озерах СИП: а) без учета в модели комплексообразуюших веществ; б) с учетом влияния гуминовых веществ. Примечание для рис. 4, 5: НА1, FA1 соответствуют карбоксильным типам соединения с гуминовыми кислотами и фульвокислотами, НА2, FА2 - фенольным функциональным группам связи металл-лиганд для этих соединений

Fig. 4. Migration forms of uranium in riverstreams and lakes of STS: a) without taking into account humic substances in modelling; b) taking into account humic substances. Note for Fig. 4, 5: HA1, FA1 correspond to carboxyl types of compounds with humic acids and fulvic acids, HA2, FA2 - phenolic functional groups of metal-ligand bonds for these compounds 
Рассчитаны формы миграции урана (рис. 4) и тория (рис. 5) в природных водах с помощью программы Minteq Visual 3.1. База данных этого программного комплекса регулярно дополняются и обновляются. Поскольку состав водоемов и водотоков существенно отличался, было решено рассмотреть их по отдельности. Выделены формы нахождения тория и урана с учетом и без учета гуминовых веществ для того, чтобы была возможность сравнить, насколько может изменяться картина в присутствии комплексообразующих веществ. В модель были заложены все компоненты, перечисленные в табл. 1. Отдельно моделировались формы миграции с учетом гуминовых веществ и без них.

Программный комплекс также позволяет рассчитать индексы насыщения по основным породообразующим минералам и специфичным в этом исследовании минералам урана и тория. Эти данные могут быть использованы для интерпретации данных при изучении процессов осаждения радиоактивных элементов с теми или иными фазами.

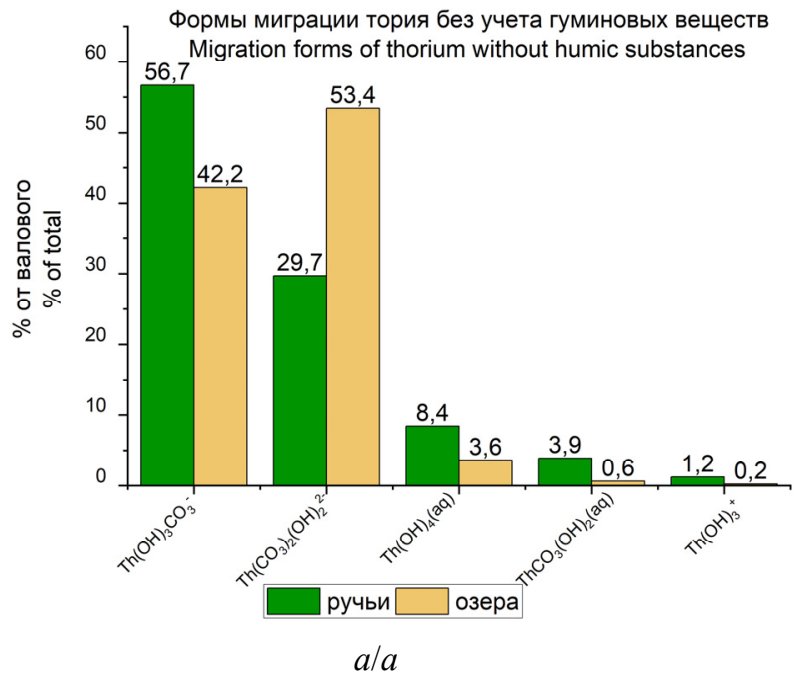

При расчете форм миграции урана было установлено, что уранилкарбонат кальция будет преобладать, вне зависимости от состава воды и учета гуминовых веществ. Преобладание именно такой формы миграции в природных водах было экспериментально подтверждено и неразрушающим методом рентгеновской спектроскопии поглощения ранее в работе Г. Бернарда с соавторами [52].

При добавлении в модель гуминовых веществ доминантная форма миграции остается неизменной. Однако для маломинерализованных вод ручьев появляется существенная доля миграционной формы урана, связанной с фенольными функциональными группами гуминовых кислот. При этом, согласно расчетам, среди органических форм для ручьев существенную роль будут играть гуматные комплексы (до 30 \% от суммы форм миграции), а в водоемах - фульватные. В целом по результатам моделирования видно, что роль гуминовых веществ в водоемах ниже, чем в водах ручьев. Это может быть связано с тем, что в водах с более высокой ионной силой устойчивость неорганических комплексов выше.

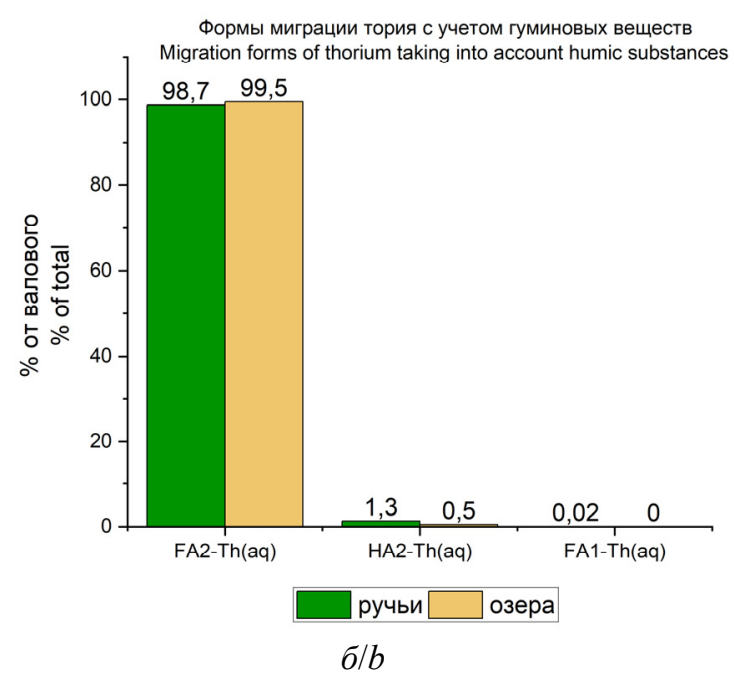

Pис. 5. Формы миграции тория в ручьях и озерах СИП: а) без учета в модели гуминовых веществ; б) с учетом влияния гуминовых веществ

Fig. 5. Migration forms of thorium in riverstreams and lakes of STS: a) without taking into account humic substances in modelling; b) taking into account humic substances

При добавлении в модельную систему для расчетов гуминовых веществ для тория картина распределения его форм миграции существенно меняется. Так, весь торий связывается фенольными функциональными группами фульвокислот. Лишь небольшая его часть взаимодействует с аналогичными группами гуминовых кислот. Выведение тория с коллоидами и взвесями также может быть следствием его выведения с ассоциатами высокомолекулярных органических веществ либо с органоминеральными коллоидами, где одним из компонентов являются фульвокислоты. Поскольку в природных водах практически всегда присутствуют органические вещества гуминовой природы, при детальном рассмотрении особенностей миграции тория, с одной стороны, можно было бы пренебречь его неорганическими комплексами. Од- нако необходимо учитывать ограниченность модели только железом. Данный элемент был включен в модель как элемент, имеющий самые высокие константы устойчивости среди большинства изученных металлов. Однако в присутствии элементов, имеющих более высокие или сопоставимые константы устойчивости с фульво- и гуминовыми кислотами для тория, например меди, кобальта и др., вся доступная для комплексообразования органическая составляющая будет расходоваться. И в таком случае миграция тория, равно как и урана, будет определяться неорганическими комплексами, которые и были рассмотрены в работе.

Опираясь на суждения авторов [36 и др.], мы выделили градацию по индексу насыщения $0 \geq \mathrm{SI} \geq-0,3$ как равновесную либо близкую к равновесию. Таким 
образом, пресные гидрокарбонатные нейтральные воды ручьев площадки «Дегелен» по величине SI (табл. 3) были насыщены только относительно кварца и близки к насыщению кальцитом (равновесны).

Таблица 3. Индексы насыщения (SI) основных минералов в водных объектах СИП

Table 3. $\quad$ Saturation indexes (SI) for main mineral phases in water bodies of STS

\begin{tabular}{|c|c|c|}
\hline Основные минералы, & $\begin{array}{c}\text { Ручьи } \\
\text { Waterstreams }\end{array}$ & Озера/Lakes \\
\hline $\begin{array}{c}\text { достигшие } \\
\text { насыщения } \\
\text { Main minerals at } \\
\text { saturation point and } \\
\text { above (SI }>0) \\
\text { либо близкие к рав- } \\
\text { новесию } \\
\text { or near equilibrium } \\
(0,3 \geq \mathrm{SI} \geq-0,3)\end{array}$ & $\begin{array}{c}\text { Кварц } \\
\text { Quartz }(0,4) \\
\text { Кальцит } \\
\text { Calcite } \\
(-0,08)\end{array}$ & $\begin{array}{c}\text { Торианит/Thorianite }(4,9) \\
\text { Каолинит/Kaolinite }(3,3) \\
\text { Доломит/Dolomite }(1,9) \\
\text { Арагонит/Aragonite }(0,75) \\
\text { Кальцит/Calcite }(0,89) \\
\text { Кварц/Quartz }(0,04) \\
\text { Гипс/Gypsum }(-0,27) \\
\text { минералы группы железа } \\
\text { и др. } \\
\text { iron minerals etc. }\end{array}$ \\
\hline
\end{tabular}

Воды водоемов, состав которых использовался для расчетов в модели, будут насыщены по карбонатам кальция и магния, минералам группы железа и отдельным алюмосиликатам. По отношению к гипсу и кварцу воды можно считать равновесными. Формирование торианита, несмотря на высокий индекс насыщения, остается дискуссионным ввиду крайне малого его количества. Возможно, наличие других акцессорных фаз будет инициировать развитие его нестехиометрических соединений.

Таким образом, при высаживании перечисленных вторичных минералов для водоемов будет очевиден более активный вынос естественных радионуклидов при их соосаждении и сорбции на данных фазах.

\section{Заключение}

Полученные результаты в совокупности позволяют более объективно взглянуть на особенности переноса в водной среде природных радиоактивных элементов и обозначить процессы, которые в значительной степени его определяют. Сульфат-ион в водах ручьев является индикатором интенсивности водообмена и скорости

\section{СПИСОК ЛИТЕРАТУРЫ}

1. Medved I., Černý R. Modeling of radionuclide transport in porous media: a review of recent studies // Journal of Nuclear Materials. 2019. - V. 526. - 151765.

2. Regional geochemical survey of concealed sandstone-type uranium deposits using fine-grained soil and groundwater in the Erlian basin, north-east China / B. Zhang, X. Wang, J. Zhou, Z. Han, Q. Liu, W. Wang, R. Li, B. Zhang, B. Dou // Journal of Geochemical Exploration. - 2020. - V. 216. - 106573. URL: https://doi.org/10.1016/j.gexplo.2020.106573 (дата обращения 15.09.2020)

3. Uranium in the environment. Mining impact and consequences Eds. B. Merkel, A. Hasche-Berger. - Berlin; Heidelberg: SpringerVerlag, 2006. - $896 \mathrm{p}$

4. Uranium aqueous speciation in the vicinity of the former uranium mining sites using the diffusive gradients in thin films and ultrafiltration techniques / J. Drozdzak, M. Leermakers, Y. Gao, M. Elskens, V. Phrommavanh, M. Descostes // Analytica Chimica Acta. - 2016. - V. 913. - P. 94-103. URL: https://doi.org/ 10.1016/j.aca.2016.01.052 (дата обращения 15.09.2020). окисления сульфидных минералов, в результате чего высвобождаются в раствор значительные концентрации урана. Размеры и форма ореола рассеяния урана будут определяться наличием геохимических барьеров на пути водных потоков, ограничиваясь при росте минерализации и распространяясь при увеличении концентрации гуминовых веществ в воде.

Уран как более сильный мигрант в условиях поверхностных вод преимущественно связан с органическими и органоминеральными комплексами, а также в большей степени подвержен трансформации форм нахождения в случае изменения геохимических условий среды. Для обоих элементов характерна миграция в виде коллоидных частиц. При этом для тория коллоидный транспорт более выражен.

Доминирующей миграционной формой как тория, так и урана являются взвешенные компоненты природных вод, которые определяют более 50 \% от суммы всех форм нахождения. На расстоянии 9 км от источника поступления в воду радионуклидов, в долине ручья Карабулак, общее содержание урана падало более чем на порядок, а тория - в 3-6 раз. При этом $\mathrm{Th} / \mathrm{U}$ в растворенной форме остается более стабильным на данном участке, по сравнению с коллоидными и взвешенными формами. Повышенные отношения $\mathrm{Th} / \mathrm{U}$ во взвешенной форме отражают происхождение тория в этой фракции - выветривание горных пород. Более низкие отношения этих элементов для растворенной формы показывают способность урана проявлять высокое сродство к комплексообразованию и миграции с растворенным органическим веществом гуминовыми и фульвокислотами. При сопоставлении $\mathrm{Th} / \mathrm{U}$ в коллоидной форме для вод с разным гидродинамическим режимом прослеживается и степень выраженности влияния терригенной составляющей. В воде водоемов $\mathrm{Th} / \mathrm{U}$ выше почти на порядок, вероятно, за счет более медленного водообмена и обогащения воды торием в процессе выщелачивания из горных пород.

Исследование выполнено при финансовой поддержке РФФИ в рамках научного проекта № 19-33-60030.

5. Radiological and pollution risk assessments of terrestrial radionuclides and heavy metals in a mineralized zone of the siwalik region (India) / P. Pandit, P. Mangala, A. Saini, P. Bangotra, V. Kumar, R. Mehra, D. Ghosh // Chemosphere. - 2020 - - V. 254. 126857. URL: https://doi.org/10.1016/j.chemosphere.2020.126857 (дата обращения 15.09.2020).

6. Weathering and evaporation controls on dissolved uranium concentrations in groundwater - a case study from northern Burundi / V.E.A. Post, S.I. Vassolo, C. Tiberghien, D. Baranyikwa, D. Miburo // Science of the Total Environment. - 2017. - V. 607-608. P. 281-293. URL: https://doi.org/10.1016/j.scitotenv.2017.07.006 (дата обращения 15.09.2020).

7. Alkinani M., Kanoua W., Merkel B. Uranium in groundwater of the Al-Batin Alluvial Fan aquifer, south Iraq // Environmental Earth Sciences. - 2016. - V. 75. - № 10. - P. 1-13. URL: https://doi.org/10.1007/s12665-016-5685-3 (дата обращения 15.09.2020).

8. Uranium isotope composition of waters from South Texas uranium ore deposits / C.J. Placzek, J.M. Heikoop, B. House, B.S. Linhoff, M. Pelizza // Chemical Geology. - 2016. - V. 437. - P. 44-55. URL: https://doi.org/10.1016/j.chemgeo.2016.05.008 (дата обрашения 15.09.2020). 
9. Co-transport of $\mathrm{U}(\mathrm{VI})$ and gibbsite colloid in saturated granite particle column: role of $\mathrm{pH}, \mathrm{U}(\mathrm{VI})$ concentration and humic acid / J. Yang, Z. Zhang, Z. Chen, M. Ge, W. Wu, Z. Guo // Science of the Total Environment. - 2019. - V. 688. - P. 450-461. URL: https://doi.org/10.1016/j.scitotenv.2019.05.395 (дата обращения 15.09.2020).

10. Toropov A.S. Migration forms of anthropogenic radionuclides in tunnel waters at the Degelen Mountains, Semipalatinsk Test Site // Geochemistry International. - 2020. - V. 58. - № 3. - P. 342-351.

11. Торопов А.С. Фракционирование форм нахождения техногенных радионуклидов в водных объектах Семипалатинского испытательного полигона // Известия Томского политехнического университета. Инжиниринг георесурсов. - 2018. T. 329. - № 6. - С. 74-84.

12. Каюков П.Г. Изучение радиационной обстановки на территории Республики Казахстан. Отчет за 2004-2008 гг. - Алматы: Волковгеология, 2008. - Т. 2. Восточно-Казахстанская область. -177 с.

13. Comparative analysis of water contamination of the Shagan river at the Semipalatinsk test site with heavy metals and artificial radionuclides / I. Gorlachev, P. Kharkin, M. Dyussembayeva, S. Lukashenko, G. Gluchshenko, L. Matiyenko, D. Zheltov, A. Kitamura, N. Khlebnikov // Journal of Environmental Radioactivity. - 2020. - V. 213. - 06110. URL https://doi.org/10.1016/ j.jenvrad.2019.106110 (дата обращения 15.09.2020).

14. Мальковский В.И., Юдинцев Р.В. Модель коллоидного переноса радионуклидов подземными водами // Доклады Академии наук. - 2016. - T. 470. - № 1. - C. 87-90. URL https://doi.org/10.1134/S1028334X16090051 (дата обращения 15.09.2020)

15. Ure A.M., Davidson C.M. Chemical speciation in the environment. - Glasgow: Blackwell Science, 2002. - 452 p.

16. Radioactive particles in the environment: sources, particle characterization and analytical techniques. IAEA-TECDOC1663. - Vienna: International Atomic Energy agency, 2011. - $90 \mathrm{p}$

17. McCarthy J.F., Zachara J.M. Subsurface transport of contaminants // Environmental Science Technology. - 1989. - V. 23. - P. 496-502

18. Migration of plutonium in ground water at the Nevada Test Site / A.B. Kersting, D.W. Efurd, D.L. Finnegan, D.J. Rokop, D.K. Smith, J.L. Thompson // Nature. - 1999. - V. 397 (6714). P. 56-59.

19. Markich S.J., Brown P.L. Actinide speciation and bioavailability in fresh and marine waters // The heaviest metals: science and technology of the actinides and beyond / Eds. W.J. Evans, T.P. Hanusa. - USA: Wiley, 2018. - P. 367-400. URL https://doi.org/10.1002/9781119951438.eibc2559 (дата обращения 15.09.2020).

20. Environmental colloids and particles: behavior, separation and characterization / Eds. K.J. Wilkinson, J.R. Lead. - England: Wiley, 2007. $-502 \mathrm{p}$.

21. Speciation, size fractionation and transport of trace elements in the continuum soil water-mire-humic lake-river-large oligotrophic lake of a Subarctic watershed / S.M. Ilina, S.A. Lapitskiy, Y.V. Alekhin, J. Viers, M. Benedetti, O.S. Pokrovsky // Aquatic Geochemistry. - 2016. - V. 22. - P. 65-95.

22. Novikov A.P. Migration and concentration of artificial radionuclides in environmental objects // Geochemistry International. - 2010. - V. 48. - № 13. - P. 1263-1387.

23. Trace element speciation in natural waters using hollow-fiber ultrafiltration / E. Lydersen, H.E. Bjornstad, B. Salbu, A.C. Pappas // Speciation of metals in water, sediment and soil systems / Ed. by L. Landner. - Berlin; Heidelberg: Springer, 1987. - V. 11 - P. 85-97.

24. Transport of low $240 \mathrm{Pu} / 239 \mathrm{Pu}$ atom ratio plutonium-species in the $\mathrm{Ob}$ and Yenisey Rivers to the Kara Sea / O.C. Lind, D.H. Oughton, B. Salbu, L. Skipperud, M.A. Sickel, J.E. Brown // Earth and Planetary Science Letters. - 2006. - V. 251. - № 1-2. P. 33-43.

25. Challenges associated with the behaviour of radioactive particles in the environment / B. Salbu, V. Kashparov, O.C. Lind, R. GarciaTenorioc, M.P. Johansen, D.P. Child, R.C. Sanchof // Journal of Environmental Radioactivity, - 2018 - V. 186. - P. 101-115.

26. Bouby M., Finck N., Geckeis H. Flow field-flow fractionation (FIFFF) coupled to sensitive detection techniques: a way to examine radionuclide interactions with nanoparticles // Mineralogical Magazine. - 2012. - V. 76. - № 7. - P. 2709-2721.

27. Suspended particulate matter determines physical speciation of Fe, $\mathrm{Mn}$, and trace metals in surface waters of Loire watershed / M. Baalousha, S. Stoll, M. Motelica-Heino, N. Guigues, G. Braibant, F. Huneau, P. le Coustumer // Environmental Science Pollution Research. - 2019. - V. 26. - № 6. - P. 5251-5266. URL: https://doi.org/10.1007/s11356-018-1416-5 (дата обращения $15.09 .2020)$

28. Speciation of trace metals in pond water as studied by liquid chromatography/inductively coupled plasma mass spectorometry / A. Itoh, C. Kimata, H. Miwa, H. Sawatari, H. Haraguchi // Bulletin of Chemical Society of Japan. - 1996. - V. 69. - № 12. - P. 3469-3473.

29. Multielement characterization of metal-humic substances complexation by size exclusion chromatography, asymmetrical flow field-flow fractionation, ultrafiltration and inductively coupled plasma-mass spectrometry detection: A comparative approach / E. Bolea, M.P. Gorriz, M. Bouby, F. Laborda, J.R. Castilloa, H. Geckeis // Journal of Chromatography A. 2006. - V. 1129. - № 2. - P. 236-246.

30. Mineral-water interface reactions of actinide / H. Geckeis, J. Lützenkirchen, R. Polly, T. Rabung, M. Schmidt // Chemical Reviews. - 2013. - V. 113. - № 2. - P. 1016-1062. URL: https://doi.org/10.1021/cr300370h (дата обращения 15.09.2020).

31. Results of the colloid and radionuclide retention experiment at the Grimsel Test Site (GTS), Switzerland-impact of reaction kinetics and speciation on radionuclide migration / H. Geckeis, T. Schafer, W. Hauser, T. Rabung, T. Missana, C. Degueldre, A. Mori, J. Eikenberg, Th. Fierz, W.R. Alexander // Radiochimica Acta. 2004. - V. 92. - № 9-11. - P. 765-774.

32. Investigation of uranium-colloid interactions in soil by dual fieldflow fractionation/capillary electrophoresis hyphenated with inductively coupled plasma-mass spectrometry / C. ClaveranneLamolre, J. Aupiais, G. Lespes, J. Frayret, E. Pili, F. Pointurier, M. Potin-Gautier // Talanta. - 2011. - V. 85. - № 5. - P. 2504-2510. URL: https://doi.org/10.1016/j.talanta.2011.07.100 (дата обращения 15.09.2020).

33. Langmuir D. Aqueous environmental geochemistry. - Upper Saddle River, N.J.: Prentice Hall, 1997. - 600 p.

34. Uranium speciation in weathered granitic waste rock piles: an XAFS investigation / A. Tayal, S.D. Conradson, A. Kanzari, F. Lahrouch, M. Descostes, M. Gerard // RSC Advances. - 2019. V. 9. - № 21. - P. 11762-11773. URL: https://doi.org/10.1039/c9ra00961b (дата обращения 15.09.2020).

35. Romanchuk A.Y., Vlasova I.E., Kalmykov S.N. Speciation of uranium and plutonium from nuclear legacy sites to the environment: a mini review // Frontiers in Chemistry. - 2020. V. 8. - P. 1-10.

36. Колпакова М.Н., Гаськова О.Л., Наймушина О.Р. Озеро Эбейты, Россия: химико-органический и минеральный состав воды и донных отложений // Известия Томского политехнического университета. Инжиниринг георесурсов. - 2018. - Т. 329. № 1. - P. 111-123.

37. Update on the chemical thermodynamics of uranium, neptunium, plutonium, americium and technetium / R. Guillaumont, T. Fanghänel, J. Fuger, I. Grenthe, V. Neck, D.A. Palmer, M.H. Rand // Chemical thermodynamics series / Eds. F.J. Mompean et al. - Michigan: Elsevier Science, 2003. - V. 5 $918 \mathrm{p}$.

38. A modelling exercise on the importance of ternary alkaline earth carbonate species of uranium(VI) in the inorganic speciation of natural waters / T. Vercouter, P.E. Reiller, E. Ansoborlo, L. Février, R. Gilbin, C. Lomenech, V. Philippini // Applied Geochemistry. - 2015. - V. 55. - P. 192-198.

39. Mahoney J.J., Jakubowski R.T. Assessment of uranyl sorption constant on ferrihydrite - comparison of model derived constants and updates to the diffuse layer model database // Uranium, mining and hydrogeology / Eds. B. Merkel, A. Hasche-Berger. Berlin; Heidelberg: Springer, 2008. - P. 919-928.

40. Di Bonito M., Lofts S., Groenenberg J.E. Models of geochemical speciation: structure and application // Environmental geochemistry. Site characterization, data analysis and case histories. $2^{\text {nd }}$ ed. / Ed. by B. de Vivo. - Amsterdam: Elsevier, 2018. - P. 237-305. 
41. Reiller P.E., Descostes M. Development and application of the thermodynamic database PRODATA dedicated to the monitoring of mining activities from exploration to remediation // Chemosphere. - 2020. - V. 251. - 126301. URL: https://doi.org/ 10.1016/j.chemosphere.2020.126301 (дата обращения 15.09.2020).

42. Semipalatinsk test site. Present state. $3^{\text {rd }}$ ed. / Eds. E.G. Batyrbekov, S.N. Lukashenko. - Pavlodar: Press House, 2017. - 52 p.

43. Казакова Ю.И. Техногенная трещиноватость и химический состав вод зоны фильтрации горного массива Дегелен // Вестник НЯЦ РК. - 2005. - № 4. - С. 84-89.

44. Nazarbayev N.A., Shkolnik V.S., Batyrbekov E.G. Scientific, technical and engineering work to ensure the safety of the former Semipalatinsk Test Site. V. 1. - London: WorldWide Promedia, 2017. $-304 \mathrm{p}$.

45. Aquatic chemistry: chemical equilibria and rates in natural waters. $3^{\text {rd }}$ ed. / Eds. W. Stumm, J.J. Morgan. - New York: Wiley, 1995. $1040 \mathrm{p}$.

46. Ферронский В.И., Поляков В.А. Изотопия гидросферы земли. - М.: Научный мир, 2009. - 632 с

47. Раимканова А.М., Айдарханова А.К., Лукашенко С.Н. Выщелачивание техногенных радионуклидов из грунта зоны навала «Атомного» озера на территории Семипалатинского испытательного полигона // Ядерная и радиационная физика: Материалы 10 Международной конференции. - Курчатов, 2015. C. 167
48. Zamana L.V. Isotopes of hydrogen and oxygen in nitrogen hot springs of Baikal Rift Zone in terms of interaction in the waterrock system // Doklady Earth Sciences. - 2012. - V. 442. - № 1. P. 81-85.

49. Рихванов Л.П. Радиоактивность и радиоактивные элементы как фактор геологической среды и его использование в науках о Земле // Разведка и охрана недр. - 2017. - № 12. - С. 55-61.

50. Degueldre C., Joyce M.J. Evidence and uncertainty for uranium and thorium abundance: a review // Progress of the Nuclear Energy. - 2020. - V. 124. - № 4. - 103299. URL: https://doi.org/ 10.1016/j.pnucene.2020.103299 (дата обращения 15.09.2020).

51. Уран и торий в природных водах юго-востока Алтае-Саянской области / Ю.Г. Копылова, Н.В. Гусева, К.Д. Аракчаа, А.А. Хващевская, И.С. Мазурова, О.Д. Аюнова, Ч.К. Ойдуп, К.М. Рычкова // Радиоактивность и радиоактивные элементы в среде обитания человека: Материалы V Международной конференции. - Томск: Изд-о ТПУ, 2016. - С. 339-345.

52. Uranyl(VI) carbonate complex formation: Validation of the $\mathrm{Ca}_{2} \mathrm{UO}_{2}\left(\mathrm{CO}_{3}\right)_{3}$ (aq.) species / G. Bernhard, G. Geipel, T. Reich, V. Brendler, S. Amayri, H. Nitsche // Radiochimica Acta. 2001. - V. 89. - № 8. - P. 511-518. URL: https://doi.org/10.1524/ract.2001.89.8.511 (дата обращения 15.09.2020)

Поступила 31.08.2020 2.

\section{Информация об авторах}

Toponoв A.C., кандидат геолого-минералогических наук, старший научный сотрудник кафедры радиохимии химического факультета Московского государственного университета имени М.В. Ломоносова.

Cолдатова $\boldsymbol{E} . \boldsymbol{A}$., кандидат геолого-минералогических наук, старший научный сотрудник лаборатории моделирования гидрогеохимических и гидротермальных процессов Института геохимии и аналитической химии им. В.И. Вернадского Российской академии наук.

Рихванов Л.П., доктор геолого-минералогических наук, профессор, профессор отделения геологии Инженерной школы природных ресурсов Национального исследовательского Томского политехнического университета. 
UDC 550.424.6:54.01(546.791+546.795):556:550.845

\title{
FORMS OF RADIONUCLIDES (U AND Th) MIGRATION IN NATURAL WATERS UNDER DIFFERENT GEOCHEMICAL CONDITIONS BASED ON COMPUTATIONAL AND EXPERIMENTAL DATA
}

\author{
Andrey S. Toropov ${ }^{1}$, \\ torop990@gmail.com
}

\author{
Evgeniya A. Soldatova², \\ sea@geokhi.ru
}

\author{
Leonid P. Rikhvanov $^{3}$ \\ 1 Lomonosov Moscow State University, \\ 1, Leninskie Gory, Moscow, 119991, Russia. \\ 2 Vernadsky Institute of Geochemistry and Analytical Chemistry Russian Academy of Sciences, \\ 19, Kosygin street, Moscow, 119991, Russia. \\ 3 National Research Tomsk Polytechnic University, \\ 30, Lenin avenue, Tomsk, 634050, Russia.
}

The relevance of the study is caused by the necessity to take into account the diversity of the migration forms of radionuclides under geochemical conditions changes, as well as prognosis of the radioecological status of hydroecosystems. On the territory of the Semipalatinsk Test Site, the migration of natural radionuclides in water systems is poorly investigated, the calculation of the migration forms of uranium and thorium with a change in geochemical conditions will be informative for understanding the migration of a wide range of transuranium radionuclides.

The aim of the research is to determine the forms of migration of uranium and thorium in natural waters depending on the particle size and, taking into account a wide range of components, to calculate the forms of their migration in waterstreams and lakes.

Objects: water of streams of the Degelen mountain massif, water of lakes of experimental sites of the Semipalatinsk Test Site, model hydrogeochemical systems.

Methods. Speciation of natural radionuclides were investigated in situ using the method of cascade fractionation. The $\mathrm{pH}$ and Eh of the waters were determined by potentiometry, total dissolved solids was determined by conductometry. The main water ions and some elements were determined by titrimetric $\left(\mathrm{HCO}_{3}{ }^{-}, \mathrm{CO}_{3}{ }^{2-}, \mathrm{Cl}, \mathrm{Ca}^{2+}, \mathrm{Mg}^{2+}\right)$, optical emission spectrometry $(\mathrm{Na}, \mathrm{K}, \mathrm{Ca}, \mathrm{Mg}, \mathrm{Fe}$, Si), and ion chromatography $\left(\mathrm{Cl}, \mathrm{SO}_{4}{ }^{2-}\right)$. The content of dissolved organic substances was determined by the permanganate and dichromate oxidation, the method of catalytic combustion, and the intensity of the UV signal. The content of $U$ and Th was determined by mass spectrometry.

Results. The features of $U$ and Th transfer in different water bodies of Semipalatinsk Test Site are determined. The processes that control them are indicated. It was found that the sulfate ion in waterstreams is an indicator of water exchange intensity and the rate of oxidation of sulfide minerals, which determine the release of uranium significant concentrations into the solution. Uranium is associated with organic and organomineral complexes and is subjected to transformation of migration forms in the event of changes in the geochemical conditions of the environment. Thorium is more characterized by colloidal transport than uranium. Suspended components of natural waters dominate among migration forms of these elements. The Th/U ratio in dissolved form is rather stable compared to colloidal and suspended forms. For waters with various hydrodynamic regimes, there is a difference in the severity of the influence of the terrigenous component.

\section{Key words:}

Uranium, thorium, colloids, modeling, geochemical conditions, migration, calcium uranyl carbonate, radionuclides, minerals.

The reported study was funded by RFBR, project number no. 19-33-60030.

\section{REFERENCES}

1. Medved I., Černý R. Modeling of radionuclide transport in porous media: a review of recent studies. Journal of Nuclear Materials, 2019, vol. 526, 151765.

2. Zhang B., Wang X., Zhou J., Han Z., Liu Q., Wang W., Li R., Zhang B., Dou B. Regional geochemical survey of concealed sandstone-type uranium deposits using fine-grained soil and groundwater in the Erlian basin, north-east China. Journal of Geochemical Exploration, 2020, vol. 216, 106573. Available at: https://doi.org/10.1016/j.gexplo.2020.106573 (accessed 15 September 2020).

3. Uranium in the environment. Mining impact and consequences. Eds. B. Merkel, A. Hasche-Berger). Berlin, Heidelberg, SpringerVerlag, 2006. $896 \mathrm{p}$.

4. Drozdzak J., Leermakers M., Gao Y., Elskens M., Phrommavanh V., Descostes M. Uranium aqueous speciation in the vicinity of the former uranium mining sites using the diffusive gradients in thin films and ultrafiltration techniques. Analytica Chimica Acta, 2016, vol. 913, pp. 94-103. Available at: https://doi.org/10.1016/j. aca.2016.01.052 (accessed 15 September 2020).

5. Pandit P., Mangala P., Saini A., Bangotra P., Kumar V., Mehra R., Ghosh D. Radiological and pollution risk assessments of terrestrial radionuclides and heavy metals in a mineralized zone of the siwalik region (India). Chemosphere, 2020, vol. 254, 126857. Available at: https://doi.org/10.1016/j.chemosphere.2020.126857 (accessed 15 September 2020).

6. Post V.E.A., Vassolo S.I., Tiberghien C., Baranyikwa D., Miburo D. Weathering and evaporation controls on dissolved uranium concentrations in groundwater - a case study from northern Burundi. Science of the Total Environment, 2017, vol. 607-608, pp. 281-293. Available at: https://doi.org/10.1016/j.scitotenv. 2017.07.006 (accessed 15 September 2020).

7. Alkinani M., Kanoua W., Merkel B. Uranium in groundwater of the Al-Batin Alluvial Fan aquifer, south Iraq. Environmental Earth 
Sciences, 2016, vol. 75, no. 10, pp. 1-13. Available at: https://doi.org/10.1007/s12665-016-5685-3 (accessed 15 September 2020).

8. Placzek C.J., Heikoop J.M., House B., Linhoff B.S., Pelizza M Uranium isotope composition of waters from South Texas uranium ore deposits. Chemical Geology, 2016, vol. 437, pp. 44-55. Available at: https://doi.org/10.1016/j.chemgeo.2016.05.008 (accessed 15 September 2020).

9. Yang J., Zhang Z., Chen Z., Ge M., Wu W., Guo Z. Co-transport of U(VI) and gibbsite colloid in saturated granite particle column: role of $\mathrm{pH}, \mathrm{U}(\mathrm{VI})$ concentration and humic acid. Science of the Total Environment, 2019, vol. 688, pp. 450-461. Available at: https://doi.org/10.1016/j.scitotenv.2019.05.395 (accessed 15 September 2020)

10. Toropov A.S. Migration forms of anthropogenic radionuclides in tunnel waters at the Degelen Mountains, Semipalatinsk Test Site. Geochemistry International, 2020, vol. 58, no. 3, pp. 342-351.

11. Toropov A.S. Fractionation of technogenic radionuclides species in water bodies of Semipalatinsk Test Site. Bulletin of the Tomsk Polytechnic University. Geo Assets Engineering, 2018, vol. 329, no. 6, pp. 74-84. In Rus.

12. Kayukov P.G. Izuchenie radiatsionnoy obstanovki na territorii Respubliki Kazahstan [Study of the radiation situation on the territory of the Republic of Kazakhstan]. Otchet za 2004-2008 gg [Report for 2004-2008]. Almaty, Volkovgeologiya Publ., 2008. Vol. 2. East Kazakhstan region. $177 \mathrm{p}$

13. Gorlachev I., Kharkin P., Dyussembayeva M., Lukashenko S., Gluchshenko G., Matiyenko L., Zheltov D., Kitamura A., Khlebnikov N. Comparative analysis of water contamination of the Shagan river at the Semipalatinsk test site with heavy metals and artificial radionuclides. Journal of Environmental Radioactivity, 2020, vol. 213, 06110. Available at: https://doi.org/10.1016/j. jenvrad.2019.106110 (accessed 15 September 2020).

14. Malkovsky V.I., Yudintsev S.V. Model of colloidal transportation of radionuclides by groundwater. Doklady Earth Sciences, 2016, vol. 470, no. 1, pp. 942-945. Available at: https://doi.org/ 10.1134/S1028334X16090051 (accessed 15 September 2020).

15. Ure A.M. Davidson C.M. Chemical speciation in the environment. Glasgow, Blackwell Science, 2002. 452 p.

16. Radioactive particles in the environment: sources, particle characterization and analytical techniques. IAEA-TECDOC-1663. Vienna, International Atomic Energy agency, 2011.90 p.

17. McCarthy J.F., Zachara J.M. Subsurface transport of contaminants Environmental Science Technology, 1989, vol. 23, pp. 496-502.

18. Kersting A.B., Efurd D.W., Finnegan D.L., Rokop D.J., Smith D.K., Thompson J.L. Migration of plutonium in ground water at the Nevada Test Site. Nature, 1999, vol. 397 (6714), pp. 56-59.

19. Markich S.J., Brown P.L. Actinide speciation and bioavailability in fresh and marine waters. The heaviest metals: science and technology of the actinides and beyond. Eds. W.J. Evans, T.P. Hanusa. USA, Wiley, 2018. pp. 367-400. Available at: https://doi.org/ 10.1002/9781119951438.eibc2559 (accessed 15 September 2020).

20. Environmental colloids and particles: behavior, separation and characterization. Eds. K.J. Wilkinson, J.R. Lead. England, Wiley, 2007. $502 \mathrm{p}$

21. Ilina S.M., Lapitskiy S.A., Alekhin Y.V., Viers J., Benedetti M., Pokrovsky O.S. Speciation, size fractionation and transport of trace elements in the continuum soil water-mire-humic lakeriver-large oligotrophic lake of a Subarctic watershed. Aquatic Geochemistry, 2016, vol. 22, pp. 65-95.

22. Novikov A.P. Migration and concentration of artificial radionuclides in environmental objects. Geochemistry International, 2010 vol. 48 , no. 13 , pp. $1263-1387$.

23. Lydersen E., Bjornstad H.E., Salbu B., Pappas A.C. Trace element speciation in natural waters using hollow-fiber ultrafiltration. Speciation of metals in water, sediment and soil systems. Ed. by L. Landner. Berlin, Heidelberg, Springer, 1987. Vol. 11, pp. 85-97.

24. Lind O.C., Oughton D.H., Salbu B., Skipperud L., Sickel M.A., Brown J.E. Transport of low $240 \mathrm{Pu} / 239 \mathrm{Pu}$ atom ratio plutoniumspecies in the $\mathrm{Ob}$ and Yenisey Rivers to the Kara Sea. Earth and Planetary Science Letters, 2006, vol. 251, no. 1-2, pp. 33-43.

25. Salbu B., Kashparov V., Lind O.C., Garcia-Tenorioc R., Johansen M.P., Child D.P., Sanchof R.C. Challenges associated with the behaviour of radioactive particles in the environment. Journal of Environmental Radioactivity, 2018, vol. 186, pp. 101-115.
26. Bouby M. Finck N., Geckeis H. Flow field-flow fractionation (FIFFF) coupled to sensitive detection techniques: a way to examine radionuclide interactions with nanoparticles. Mineralogical Magazine, 2012, vol. 76, no. 7, pp. 2709-2721.

27. Baalousha M., Stoll S., Motelica-Heino M., Guigues N., Braibant G., Huneau F., Le Coustumer P. Suspended particulate matter determines physical speciation of Fe, Mn, and trace metals in surface waters of Loire watershed. Environmental Science Pollution Research, 2019, vol. 26, no. 6, pp. 5251-5266. Available at: https://doi.org/10.1007/s11356-018-1416-5 (accessed 15 September 2020).

28. Itoh A., Kimata C., Miwa H., Sawatari H., Haraguchi H. Speciation of trace metals in pond water as studied by liquid chromatography/inductively coupled plasma mass spectorometry. Bulletin of Chemical Society of Japan, 1996, vol. 69, no. 12, pp. 3469-3473.

29. Bolea E., Gorriz M.P., Bouby M., Laborda F., Castilloa J.R., Geckeis H. Multielement characterization of metal-humic substances complexation by size exclusion chromatography, asymmetrical flow field-flow fractionation, ultrafiltration and inductively coupled plasma-mass spectrometry detection: A comparative approach. Journal of Chromatography A, 2006, vol. 1129, no. 2 , pp. $236-246$.

30. Geckeis H., Lützenkirchen J., Polly R., Rabung T., Schmidt M. Mineral-water interface reactions of actinide. Chemical Reviews, 2013, vol. 113, no. 2. pp. 1016-1062. Available at: https://doi.org/10.1021/cr300370h (accessed 15 September 2020).

31. Geckeis H., Schafer T., Hauser W., Rabung T., Missana T., Degueldre C., Mori A., Eikenberg J., Fierz Th., Alexander W.R. Results of the colloid and radionuclide retention experiment at the Grimsel Test Site (GTS), Switzerland-impact of reaction kinetics and speciation on radionuclide migration. Radiochimica Acta, 2004, vol. 92, no. 9-11, pp. 765-774.

32. Claveranne-Lamolre C., Aupiais J., Lespes G., Frayret J., Pili E., Pointurier F., Potin-Gautier M. Investigation of uranium-colloid interactions in soil by dual field-flow fractionation/capillary electrophoresis hyphenated with inductively coupled plasma-mass spectrometry. Talanta, 2011, vol. 85, no. 5, pp. 2504-2510. Available at: https://doi.org/10.1016/j.talanta.2011.07.100 (accessed 15 September 2020).

33. Langmuir D. Aqueous environmental geochemistry. Upper Saddle River, N.J., Prentice Hall, 1997. 600 p.

34. Tayal A., Conradson S.D., Kanzari A., Lahrouch F., Descostes M., Gerard M. Uranium speciation in weathered granitic waste rock piles: An XAFS investigation. RSC Advances, 2019, vol. 9, no. 21, pp. 11762-11773. Available at: https://doi.org/10.1039/c9ra00961b (accessed 15 September 2020).

35. Romanchuk A.Y., Vlasova I.E., Kalmykov S.N. Speciation of uranium and plutonium from nuclear legacy sites to the environment: a mini review. Frontiers in Chemistry, 2020, vol. 8, pp. 1-10.

36. Kolpakova M.N., Gaskova O.L., Naimushina O.S. Ebeity Lake, Russia: chemical, organic and mineral composition of water and bottom sediments. Bulletin of the Tomsk Polytechnic University. Geo Assets Engineering, 2018, vol. 329, no. 1, pp. 111-123. In Rus.

37. Guillaumont R., Fanghänel T., Fuger J., Grenthe I., Neck V., Palmer D.A., Rand M.H. Update on the chemical thermodynamics of uranium, neptunium, plutonium, americium and technetium. Chemical thermodynamics series. Ed. by F.J. Mompean. Michigan, Elsevier Science, 2003. Vol. 5, 918 p.

38. Vercouter T., Reiller P.E., Ansoborlo E., Février L., Gilbin R., Lomenech C., Philippini V. A modelling exercise on the importance of ternary alkaline earth carbonate species of uranium(VI) in the inorganic speciation of natural waters. Applied Geochemistry, 2015, vol. 55, pp. 192-198.

39. Mahoney J.J., Jakubowski R.T. Assessment of uranyl sorption constant on ferrihydrite - comparison of model derived constants and updates to the diffuse layer model database. Uranium, mining and hydrogeology. Eds. B. Merkel, A. Hasche-Berger. Berlin, Heidelberg, Springer, 2008. pp. 919-928.

40. Di Bonito M., Lofts S., Groenenberg J.E. Models of geochemical speciation: structure and application. Environmental geochemistry. Site characterization, data analysis and case histories. $2^{\text {nd }}$ ed. Ed. by B. De Vivo. Amsterdam, Elsevier, 2018. pp. 237-305.

41. Reiller P.E., Descostes M. Development and application of the thermodynamic database PRODATA dedicated to the monitoring 
of mining activities from exploration to remediation. Chemosphere, 2020, vol. 251, 126301. Available at: https://oi.org/10.1016/ j.chemosphere.2020.126301 (accessed 15 September 2020).

42. Semipalatinsk test site. Present state. $3^{\text {rd }}$ ed. Eds. E.G. Batyrbekov, S.N. Lukashenko. Pavlodar, Press House, 2017. 52 p.

43. Kazakova Yu.I. Tekhnogennaya treshchinovatost i khimicheskiy sostav vod zony filtratsii gornogo massiva Degelen [Technogenic fracture and chemical composition of water filtration zone of Delegen mountain massif]. Vestnik NYAC RK, 2005, no. 4, pp. 84-89.

44. Nazarbayev N.A., Shkolnik V.S., Batyrbekov E.G. Scientific, technical and engineering work to ensure the safety of the former Semipalatinsk Test Site. Vol. 1. London, WorldWide Promedia, 2017. $304 \mathrm{p}$.

45. Aquatic chemistry: chemical equilibria and rates in natural waters. $3^{\text {rd }}$ ed. Eds. W. Stumm, J.J. Morgan. New-York, Wiley, 1995. $1040 \mathrm{p}$.

46. Ferronsky V.I., Polyakov V.A. Izotopiya gidrosfery zemli [Isotopy of the Earth's Hydrosphere]. Moscow, Nauchny mir Publ., 2009. $632 \mathrm{p}$

47. Raimkanova A.M., Aydarkhanova A.K., Lukashenko S.N. Vyshchelachivanie tekhnogennykh radionuklidov iz grunta zony navala «Atomnogo» ozera na territorii Semipalatinskogo ispytateInogo poligona [Leaching of technogenic radionuclides from the soil of the pile of the «Atomic» lake on the territory of the Semipalatinsk test site]. Materialy 10 Mezhdunarodnoy konferentsi. Yadernaya i radiatsionnaya fizika [Proc. of the $10^{\text {th }}$ International Conference. Nuclear and Radiation Physics]. Kurchatov, 2015. pp. 167.
48. Zamana L.V. Isotopes of hydrogen and oxygen in nitrogen hot springs of Baikal Rift Zone in terms of interaction in the waterrock system. Doklady Earth Sciences, 2012, vol. 442, no. 1, pp. 81-85.

49. Rihvanov L.P. Radioactivity and radioactive elements as a factor of the geological environment and its use in earth sciences. Razvedka i okhrana nedr, 2017, no. 12, pp. 55-61. In Rus.

50. Degueldre C., Joyce M.J. Evidence and uncertainty for uranium and thorium abundance: a review. Progress of the Nuclear Energy, 2020, vol. 124, no. 4, 103299. Available at: https://doi.org/ 10.1016/j.pnucene.2020.103299 (accessed 15 September 2020).

51. Kopylova Yu.G., Guseva N.V., Arakchaa K.D., Khvashchevskaya A.A., Mazurova I.S., Ayunova O.D., Oidup Ch.K., Rychkova K.M. Uran i toriy v prirodnykh vodakh yuga-vostoka Altae-Sayanskoy oblasti [Uranium and thorium in the natural waters of the South-East of the Altai-Sayan Region]. Radioaktivnost $i$ radioaktivnye elementy $v$ srede obitaniya cheloveka. Materialy $V$ Mezhdunarodnoy konferentsii [Radioactivity and radioactive elements in the human environment. Proc. of the $\mathrm{V}^{\text {th }}$ International conference]. Tomsk, TPU Publ. House, 2016. pp. 339-345.

52. Bernhard G., Geipel G., Reich T., Brendler V., Amayri S., Nitsche H. Uranyl(VI) carbonate complex formation: Validation of the $\mathrm{Ca}_{2} \mathrm{UO}_{2}\left(\mathrm{CO}_{3}\right)_{3}$ (aq.) species. Radiochimica. Acta. 2001, vol. 89 , no. 8, pp. 511-518. Available at: https://doi.org/10.1524/ract. 2001.89.8.511 (accessed 15 September 2020).

Received: 31 August 2020.

\section{Information about the authors}

Andrey S. Toropov, Cand. Sc., senior researcher, Lomonosov Moscow State University.

Evgeniya A. Soldatova, Cand. Sc., senior researcher, Vernadsky Institute of Geochemistry and Analytical Chemistry Russian Academy of Sciences.

Leonid P. Rikhvanov, Dr. Sc., professor, National Research Tomsk Polytechnic University. 